\title{
EARLY RESULTS OF FUNCTIONAL AND ANATOMIC ORGAN PRESERVATION IN STAGE I AND STAGE II LARYNGEAL CANCER USING PURE ACCELERATED RADIOTHERAPY
}

\author{
N. Rathithilagam ${ }^{1}$, P. Anandhi \\ ${ }^{1}$ Assistant Professor, Department of Radiotherapy, Government Arignar Anna Memorial Cancer Hospital and Research Institute, \\ Karapettai, Kancheepuram, Tamilnadu. \\ ${ }^{2}$ Assistant Professor, Department of Radiotherapy, Government Arignar Anna Memorial Cancer Hospital and Research Institute, \\ Karapettai, Kancheepuram, Tamilnadu.
}

\section{ABSTRACT}

\section{BACKGROUND}

Laryngeal cancer is a malignancy associated with significant psychosocial consequence as impairment of Laryngeal function from disease and its treatment results in gross disturbances in breathing, speech and swallowing with profound impact on the patient's lifestyle and self-esteem.

\section{MATERIALS AND METHODS}

Aim of this study is to assess the Local response in early Laryngeal cancer using pure accelerated radiotherapy and to determine the acute toxicity rates. The inclusion criteria, exclusion criteria, pre-treatment workup, treatment protocol, dose calculation, toxicity reporting was done. The study conducted between November 2015 and October 2016 in our Institute.

\section{RESULTS}

Between November 2015 and October 2016, thirty patients met with the eligibility criteria for the protocol and were recruited. The fractionation regimen was according to protocol specification in all patients. The duration of therapy was 39 days in 26 patients and 40 days in 4 patients. With respect to the histology and differentiation, all the 30 patients were found to have squamous cell carcinoma with Grade I histology constituting 73.3\% and Grade II histology constituting 26.4\%. No patients had progressive disease. All the 30 patients were men. Patients were assessed weekly with indirect laryngoscopy and haematological parameters on every Friday; 26 men achieved complete response at the end of treatment course; 16 out of 26 men of the above category achieved complete response at $66 \mathrm{~Gy} ; 10$ patients showed complete response 4 weeks after treatment. The other 4 patients showed complete response at the end of 6 weeks. All these 4 patients had stage II cancer, of which 2 had supraglottic cancer and 2 had glottic cancer.

\section{CONCLUSION}

In conclusion, this rather Small Single-Institutional Study showed promising results and acceptable toxicities in patients with early stages of laryngeal cancer. The present schedule is tolerated and can be safely used on an outpatient basis and even in old patients and patients with controlled comorbidities.

\section{KEYWORDS}

Laryngeal Cancer, Treatment, Toxicity, Pure Accelerated Radiotherapy.

HOW TO CITE THIS ARTICLE: Rathithilagam N, Anandhi P. Early results of functional and anatomic organ preservation in stage I and stage II laryngeal cancer using pure accelerated radiotherapy. J. Evolution Med. Dent. Sci. 2017;6(6):442-447, DOI: 10.14260/Jemds/2017/97

\section{BACKGROUND}

Laryngeal cancer is a malignancy associated with significant psychosocial consequence as impairment of laryngeal function from disease and its treatment results in gross disturbances in breathing, speech and swallowing with profound impact on the patient's lifestyle and self-esteem.

The successful management of laryngeal cancer is dependant as much upon individualising the plan of management to suit the patient and their expectation as on close co-operation among member of a multidisciplinary team.

Financial or Other, Competing Interest: None.

Submission 25-12-2016, Peer Review 10-01-2017,

Acceptance 13-01-2017, Published 19-01-2017.

Corresponding Author:

Dr. N. Rathithilagam

\#153/A, New No. 19, $5^{\text {th }}$ Street,

"C" Sector, V. G. Rao Nagar, Katpadi,

Vellore-632007, Tamilnadu.

E-mail: anbalagan_88chemco@yahoo.com

DOI: $10.14260 /$ jemds $/ 2017 / 97$

\section{Aim of the Study}

To assess the local response in early laryngeal cancer using pure accelerated radiotherapy.

To determine the acute toxicity rates.

\section{MATERIALS AND METHODS \\ Objectives}

To determine the local response rates.

To assess the rate of acute toxicity.

Patient Selection.

\section{Inclusion Criteria}

1. Age less than 70 years.

2. Patients with histological proof of squamous cell carcinoma from larynx.

3. Stage I and II of carcinoma larynx.

4. Performance status ECOG 1 and 2.

5. No distant metastasis.

6. Patients with adequate bone marrow function defined as an Absolute Peripheral Granulocyte Count (AGC) of $\geq$ 
2000 cells $/ \mathrm{mm}^{3}$, platelet count of $\geq 100,000$ cells $/ \mathrm{mm}^{3}$, adequate hepatic function with bilirubin $\leq 1.5 \mathrm{mg} \%$ and serum creatinine $\leq 1.5 \mathrm{mg} \%$.

7. Patients with a history of non-melanoma skin cancer or other previous malignancies from which the patient has remained continually disease free for $\geq 3$ years are eligible.

8. Informed consent form signed prior to study entry.

\section{Exclusion Criteria}

1. Locally advanced stages of larynx.

2. Patient with distant metastatic disease.

3. Patient with ischaemic heart disease.

4. Histology other than squamous cell carcinoma.

5. Patients with abnormal renal function test.

6. Patients with previous history of irradiation.

\section{Pre-Treatment Workup}

1. Detailed history.

2. Complete physical examination.

3. Indirect and VDL scopy and biopsy.

4. Complete haemogram and biochemistry.

5. Chest x-ray and ECG.

6. Histopathological examination.

\section{Treatment Protocol}

After explaining the nature of disease and the treatment and the expected results with an informed consent, the patients were treated with pure accelerated radiotherapy I. Radiotherapy schedule.

Radiotherapy was given using megavoltage beam to deliver a daily dose of 200 cGy per fraction, six fractions per week to a total dose of 66 Gy. Treatment commences on Monday continued up to Saturday, Sunday being the rest day over 5 - 3 weeks (38 days). An unexpected holiday in a week is compensated by giving an extra fraction on any one week day $6 \mathrm{hrs}$. after the first fraction.

\section{Physical Characteristics}

- Megavoltage linear accelerator $6 \mathrm{mv}$ photons unit used to provide appropriate photon energies.

- Treatment - distance at $80 \mathrm{~cm}$ SSD.

- Simulation films of the field and the calculation form.

- Portals were simulated.

\section{Target Volume}

Tumour with $2 \mathrm{~cm}$ clearance. Since there were no neck nodes, nodes were not treated.

\section{RT Planning}

Patient's Position - Supine with neck rest and shoulder retraction reproducibly immobilised.

Portals opposing lateral with wedged pair.

\section{Treatment Verification}

Dose Calculation

- Complete isodose curves are required.

- Appropriate Wedges were used ensure dose homogeneity.

- The variation within the target volume did not exceed $10 \%$ of the target dose.

- Institutional Ethical Committee clearance was obtained prior to the commencement of study.

\section{Toxicity Reporting}

The revised NCI Common Toxicity Criteria (CTC) Version 3.0 was used to score all chemotherapy and acute radiation $\leq \leq 90$ days) toxicities associated with this protocol except for skin and mucosa, for which RTOG criteria was used. Radiation toxicities appearing or persisting beyond 90 days from start of protocol treatment were evaluated using the RTOG Late Toxicity Scoring Scheme. With patient in treatment position, simulation films are taken for each position at the start of treatment. Treatment portals verified and corrections made if necessary.

\begin{tabular}{|c|c|c|c|c|c|}
\hline Skin & $\begin{array}{c}\text { No Change } \\
\text { Over Baseline }\end{array}$ & $\begin{array}{c}\text { Follicular, Faint } \\
\text { Erythema, Epilation, } \\
\text { Dry Desquamation }\end{array}$ & $\begin{array}{c}\text { Tender or Bright } \\
\text { Erythema, Patchy } \\
\text { Moist Desquamation }\end{array}$ & $\begin{array}{c}\text { Confluent } \\
\text { Moist } \\
\text { Desquamation }\end{array}$ & $\begin{array}{c}\text { Ulceration and } \\
\text { Haemorrhage, } \\
\text { Necrosis }\end{array}$ \\
\hline Larynx & $\begin{array}{c}\text { No Change } \\
\text { Over Baseline }\end{array}$ & $\begin{array}{c}\text { Mild or } \\
\text { Intermittent } \\
\text { Hoarseness/Cough } \\
\text { Not Requiring } \\
\text { Antitussive }\end{array}$ & $\begin{array}{c}\text { Persistent Hoarseness but Able } \\
\text { to Vocalise, Referred } \\
\text { Ear Pain, Sore throat, } \\
\text { Fibrinous exudates or Mild } \\
\text { Arytenoids Oedema } \\
\text { not Requiring Narcotic }\end{array}$ & $\begin{array}{l}\text { Whispered Speech, } \\
\text { Throat Pain or } \\
\text { Referred } \\
\text { Ear Pain Requiring } \\
\text { Narcotic/Confluent } \\
\text { Fibrinous Exudates }\end{array}$ & $\begin{array}{c}\text { Marked Dyspnoea, } \\
\text { Stridor or Haemoptysis } \\
\text { with Tracheostomy } \\
\text { or Intubation }\end{array}$ \\
\hline Pharynx & $\begin{array}{c}\text { No Change } \\
\text { Over Baseline }\end{array}$ & $\begin{array}{l}\text { Mild Dysphagia or } \\
\text { Odynophagia May } \\
\text { Require Topical } \\
\text { Anaesthetic or } \\
\text { Non-Narcotic } \\
\text { Analgesics }\end{array}$ & $\begin{array}{c}\text { Moderate } \\
\text { Dysphagia or } \\
\text { Odynophagia }\end{array}$ & $\begin{array}{l}\text { Severe Dysphagia or } \\
\text { Odynophagia with } \\
\text { Dehydration } \\
\text { or Weight Loss }>15 \%\end{array}$ & $\begin{array}{c}\text { Complete } \\
\text { Obstruction, } \\
\text { Ulceration, } \\
\text { Perforation, } \\
\text { Fistula }\end{array}$ \\
\hline
\end{tabular}




\begin{tabular}{|c|c|c|c|c|c|c|c|c|}
\hline Assessment & $\begin{array}{c}\text { Pre- } \\
\text { Treat- } \\
\text { ment }\end{array}$ & \multicolumn{5}{|c|}{$\begin{array}{c}\text { Weekly } \\
\text { During RT }\end{array}$} & $\begin{array}{c}\text { @ 4 } \\
\text { Weeks }\end{array}$ \\
\hline $\begin{array}{c}\text { History/Physical } \\
\text { Examination }\end{array}$ & + & + & + & + & + & + & + & + \\
\hline PS \& Weight & + & + & + & + & + & + & + & + \\
\hline Haemogram & + & + & + & + & + & + & + & + \\
\hline Serum Creatinine & + & + & + & + & + & + & + & + \\
\hline Blood Chemistry & + & - & - & - & - & - & - & + \\
\hline CXR & + & - & - & - & - & - & - & - \\
\hline Toxicity & - & + & + & + & + & + & + & + \\
\hline Evaluation & & + & & + & & + & + & + \\
\hline Table 2. Patient Assessments: Study Parameters \\
\hline
\end{tabular}

\section{Acute Reactions}

Local reaction of skin and mucous membranes was scored weekly during radiotherapy and post therapy until clearance.

\section{Tumour Clearance}

Response of tumour documented weekly during therapy and at each follow-up.

\section{Followup}

Response to therapy was assessed at 40 Gy with VDL Scopy. The next assessment was done immediately after completing treatment and after six weeks of treatment with VDL Scopy and CT scan neck. The patient will be followed up monthly for the first six months, at bimonthly intervals up to one year and once every three months up to three years. Patients will be followed up on six monthly basis for the next two years and annually after five years. The primary endpoint was to assess the local response at 6 weeks. Additional endpoint was to assess the acute toxicity.

\section{RESULTS}

\section{Population and Compliance to Treatment}

Between November 2015 and October 2016, thirty patients met with the eligibility criteria for the protocol and were recruited. The fractionation regimen was according to protocol specification in all patients. The duration of therapy was 39 days in 26 patients and 40 days in 4 patients.

\begin{tabular}{|c|c|c|c|}
\hline \multicolumn{2}{|c|}{ Variable } & $\begin{array}{c}\text { Number of } \\
\text { Patients }\end{array}$ & $\%$ \\
\hline \multirow{2}{*}{ Sex } & Male & 30 & $100 \%$ \\
\cline { 2 - 4 } & Female & - & - \\
\hline Age & Median & 50 Years & \\
\cline { 2 - 4 } (Years) & Range & $25-70$ Years & \\
\hline \multirow{4}{*}{ Habits } & ECOG Scale 1 & 30 & $100 \%$ \\
\cline { 2 - 4 } & Smoking & 16 & 53.5 \\
\cline { 2 - 4 } & Smoking and Tobacco & 3 & 10 \\
\hline & $\begin{array}{c}\text { Smoking and Alcohol } \\
\text { Smoking, Alcohol and } \\
\text { Tobacco }\end{array}$ & 8 & 26.5 \\
& $\begin{array}{c}\text { Table 3. Distribution of Patient } \\
\text { and Tumour Characteristics }\end{array}$ \\
\hline \multirow{2}{*}{} & \multicolumn{2}{|c}{} \\
\hline
\end{tabular}

\begin{tabular}{|c|c|c|c|}
\hline \multirow{3}{*}{ Symptoms } & Hoarseness & 22 & $73.3 \%$ \\
\hline & Dysphagia & 6 & $20 \%$ \\
\hline & Pain & 2 & $6.7 \%$ \\
\hline \multirow{2}{*}{ Site } & Glottis & 26 & $86.7 \%$ \\
\hline & Supraglottis & 4 & $13.3 \%$ \\
\hline \multirow{2}{*}{$\begin{array}{c}\text { Grade } \\
\text { (Squamous Cell } \\
\text { Carcinoma) }\end{array}$} & Grade I & 22 & $73.3 \%$ \\
\hline & Grade II & 8 & $26.4 \%$ \\
\hline \multirow[t]{2}{*}{ AJCC Stage Grouping } & Stage I & 23 & $76.6 \%$ \\
\hline & Stage II & 7 & $23.3 \%$ \\
\hline
\end{tabular}

\section{Tumour Response}

Overall tumour response to therapy was assessed in 30 patients. This included a complete response in all 30 patients. No patients had progressive disease. All the 30 patients were men. Patients were assessed weekly with indirect laryngoscopy and haematological parameters on every Friday.

26 men achieved complete response at the end of treatment course; 16 out of 20 men of the above category achieved complete response at 66Gy; 10 patients showed complete response 4 weeks after treatment. The other 4 patients showed complete response at the end of 6 weeks. All these 4 patients had stage II cancer, of which 2 had supraglottic cancer and 2 had glottic cancer. The abovementioned results showed significant statistical association by analysing through chi square test and student ' $\mathrm{p}$ ' test, $\mathrm{p}$ value $<0.01$, which was significant statistically.

\begin{tabular}{|c|c|c|}
\hline \multirow[t]{2}{*}{ Particulars } & \multicolumn{2}{|c|}{ Complete Response } \\
\hline & $\mathrm{N}$ & $(\%)$ \\
\hline Overall response & $30 / 30$ & 100 \\
\hline \multicolumn{3}{|l|}{ Grade Wise } \\
\hline Grade I & $22 / 22$ & 100 \\
\hline Grade II & $8 / 8$ & 100 \\
\hline \multicolumn{3}{|l|}{ Site Wise } \\
\hline Glottis & $26 / 26$ & 100 \\
\hline Supraglottis & $4 / 4$ & 100 \\
\hline \multicolumn{3}{|l|}{ Stage Wise } \\
\hline Glottis & $26 / 26$ & 100 \\
\hline Supraglottis & $4 / 4$ & 100 \\
\hline \multicolumn{3}{|l|}{ Stage Wise } \\
\hline Stage I & $23 / 23$ & 100 \\
\hline Stage II & $7 / 7$ & 100 \\
\hline \multicolumn{3}{|c|}{ Distribution of Tumour Response } \\
\hline
\end{tabular}

The response to Radiotherapy has significant statistical association $\mathrm{p}<0.01$, which is similar to other studies discussed in discussion.

\section{Acute Toxicity}

Skin

Only 4 out of 30 patients developed Grade III skin toxicity, the remaining patients developed Grade I or Grade II reactions.

\begin{tabular}{|c|c|c|c|}
\hline Grade I & Grade II & Grade III & Grade IV \\
\hline 8 & 18 & 4 & 0 \\
\hline \multicolumn{4}{|c|}{ Laryngeal Toxicity } \\
\hline
\end{tabular}


None of the patients suffered from acute laryngeal oedema or stridor. The rate of Grade I laryngeal mucosal toxicity was $26.6 \%$ Grade II was $60 \%$ and Grade III was 13.3\%. The acute toxicity was high, but transient. It did not need any interruption of treatment.

\section{Dysphagia}

8 patients $(26.6 \%)$ had Grade I pharyngeal toxicity, 18 patients $(60 \%)$ had Grade II toxicity and 4 patients $(13.3 \%)$ had Grade III toxicity.

Even though patient had toxicities, the toxicity value was less, that is $\mathrm{p}$ value was insignificant compared to outcome. Objective scoring parameter for assessment of improvement in voice status.

Score card with number starting from 1 to 5 was given to the patients both at the start of treatment and at the end of treatment. Patients were asked to mention the severity of hoarseness with the numbers.

1. No Hoarseness.

2. Mild Hoarseness.

3. Moderate Hoarseness.

4. Severe Hoarseness.

5. Very Severe Hoarseness.

22 patients had moderate hoarseness and 7 patients had severe hoarseness and 1 patient had very severe hoarseness at the start of treatment. At the end of treatment 23 patients had no hoarseness, 6 had mild hoarseness and 1 had moderate as told by the patients by means of numbers.

Local control improved significantly in this accelerated fractionation study. This study shows an improved cure rate in patients with less or no nodal involvement and a better local control in the primary tumour site. This better tumour site control is also reflected as an improved preservation of the larynx and voice. The benefit of accelerated fractionation in laryngeal cancer is due to its histology. Because most of the laryngeal cancers are well and moderately differentiated, which show a benefit with shortened treatment time than poorly differentiated tumours.

The DAHANCA 6 study showed a better locoregional control with low tumour classification, negative neck nodes, good performance status and treatment with six fractions per week which correlates well with the present study. No other parameters were independently associated with prognosis. The median treatment time in this study was 39 days. All patients completed treatment in 39 days, except for four patients who completed treatment in 40 days.

\section{DISCUSSION}

Laryngeal cancer is one of the most significant malignancies affecting human life because of the significant psychosocial consequences associated with the disease and its treatment. Squamous cell carcinoma is the predominant histologic type, and approximately $60 \%$ of patients will have stage III or IV disease when first evaluated. Most cases of laryngeal cancer are associated with a history of tobacco and/or alcohol use, so the treatment of patients is complicated by medical comorbidity and the development of second primary cancers. Given the fundamental role the larynx plays in human speech and communication, determining the optimal management of laryngeal cancers must involve consideration of both survival and the functional consequences of a given treatment approach. ${ }^{1}$

In most centres, RT is the initial treatment prescribed for $\mathrm{T} 1$ and $\mathrm{T} 2$ lesions with surgery reserved for salvage after RT failure, the likelihood of lymph node metastases is low, so the RT portals include only the primary site with a margin. Although, hemilaryngectomy or cordectomy produces comparable cure rates for selected $\mathrm{T} 1$ and $\mathrm{T} 2$ vocal cord lesions, RT is generally preferred. ${ }^{2}$ Supracricoid laryngectomy is a procedure designed to remove moderatesized cancers involving the supraglottic and glottis larynx. The larynx may be removed with preservation of the cricoids and the arytenoid with its neurovascular innervation and the defect is closed by approximating the base of the tongue to the remaining larynx. The oncologic and functional results of this procedure in selected patients are reported to be excellent. Transoral laser excision also may provide high cure rates for select patients with small, well-defined lesions limited to the mid-third of one true cord. A small subset of transoral laser surgeons successfully uses this technique in moderately advanced cancers. The major advantage of RT compared with partial laryngectomy is better voice quality. Partial laryngectomy finds its major use as salvage surgery in suitable cases after RT failure. The extent of disease and tumour volume in particular, are related to the likelihood of control after RT. The patient with a favourable lesion is treated with RT or a partial laryngectomy. Most patients are not candidates for the latter and are irradiated. ${ }^{3}$

Recent data suggests that the likelihood of local-regional control is better after some altered fractionation schedules compared with conventional once-daily RT. One preferred fractionation schedule is 74.4 Gy in 62 twice-daily fractions. Additionally, concomitant chemotherapy and RT has been shown to improve the likelihood of cure compared with RT alone. The optimal chemotherapy regimen is unclear. The risk of subclinical regional disease is $20 \%-30 \%$, so that the clinically negative neck is electively irradiated.

Hoarseness being the commonest and earliest symptom to present, laryngeal cancer is among the head and neck cancer to be manifested early than any site in head and neck.

All patients with T1-T2 laryngeal cancer should be treated, at least initially with intent to preserve the larynx. T1-T2 laryngeal cancer can be treated with radiation or larynx-preservation surgery with similar survival outcomes. Various surgeries are transoral laser excision, laser cordectomy, open cordectomy and partial laryngectomy. Local tumour recurrence after radiation therapy may be amenable to salvage by organ-preservation surgery, but total laryngectomy will be necessary for a substantial proportion of patients, especially those with T2 tumors. ${ }^{4}$

Concurrent chemoradiotherapy may be used for larynx preservation for patients with stage II disease. For advanced carcinoma of the larynx, organ-preservation surgery, concurrent chemoradiotherapy and radiation therapy alone, all with further surgery reserved for salvage offer potential for larynx preservation without compromising survival.

All patients should be evaluated regarding their suitability for a larynx-preservation approach, and they should be informed of these treatment options.

The age and sex distribution and the addiction patterns also correlated with data in the literature, which reports peak incidence in 50 - 70 yrs., a pre-dominant male predilection 
and association with smoking, alcohol and tobacco. Patients with all the three risk factors has a high risk of developing carcinoma. Smoking was to be a significant risk factor in the development of carcinoma. ${ }^{5}$

With regards to the presenting symptoms, the hoarseness was the presenting symptom in $79 \%$ followed by dysphagia and pain, which also correlates well with the reported data.

The most common subsite of laryngeal carcinoma found in this study was glottis $86.7 \%$ followed by supraglottis $13.3 \%$ as reported by the other studies.

With respect to the histology and differentiation, all the thirty patients were found to have squamous cell carcinoma with Grade I histology constituting $70.3 \%$ and Grade II histology constituting $26.4 \%$. According to the AJCC stage grouping, in this study there were $76.6 \%$ patients in stage I and $23.3 \%$ patients in stage II. Of the 23 stage I patients, there were 17 patients having $\mathrm{T} 1 \mathrm{a}$ lesion and 13 patients having T1b lesion.

Various studies and publications involving management of early stage laryngeal cancer reveals prolongation of overall treatment time to adversely affect the cure rates. Hence to improve the cure rates, many forms of altered fractionation radiotherapy have been tried. One among the altered fractionation is accelerated radiotherapy where the dose per fraction is $200 \mathrm{cGy}$ and the total dose remains the same which is $66 \mathrm{~Gy}$, but the overall treatment time is shortened by 38 days. This reduction in treatment time not only improves the cure results but also decreases the period of hospital stay, thereby enabling us to treat more patients where there is an increased load of patients in an Institution like ours. Accelerated radiotherapy applied to squamous cell carcinoma of the head and neck yields better locoregional control than does a conventional schedule with identical dose and fractionation. 6

This finding is in agreement with several similar but smaller randomised studies. Accelerated regimens, however, increase the treatment related morbidity and if this becomes severe it could also raise the frequency of late radiation side effects. In this study, we did see increase in acute mucositis, but it was transient and the rate of late effects did not differ from that for conventional treatment. Thus, the window of opportunity for the benefit of acceleration is narrow and with the applied radiation technique a one week reduction seems to be the optimum balance between improved tumour control and avoidance of excess late morbidity.7,8

This study was based on the DAHANCA 6. In this study, patients were treated with 6 fractions per week to a total dose of 66 Gy, which reduced the overall treatment time by 1 week. Withers et al and Bentzen and Thames showed that a dose of 0.48 Gy per day was recovered by tumour during fractionated radiotherapy of HNSCC. This was the reason why in our study in which overall treatment time was reduced by 1 week, produced higher response than conventional fractionation. By reducing overall treatment time by 1 week, the 'Dose recovery factor' of 3.3 Gy was avoided. The effect of acceleration on local control was entirely related to a better response in the tumour site than nodal response, which was shown in DAHANCA 6 study. The corollary of this finding is a better effect of acceleration in laryngeal tumours, since these tumours have less nodal involvement than those in the pharynx and oral cavity.
The histopathological differentiation of tumour might affect the response to changes in overall treatment time. Thus, prolongation of the overall treatment time through split course radiotherapy, especially decreased the outcome among patients who had moderately and well-differentiated tumours, whereas poorly differentiated were much less sensitive to variations in overall treatment time as shown by several literatures. ${ }^{9}$ The reduction of the treatment time was therefore more beneficial in the moderately-to-well differentiated tumours that overall seem to be sensitive to changes in treatment time.

The concept of effective doses was suggested by Jack Flower based on LQ model. Based on the calculations, we have delivered 72.4 Gy in 5.3 weeks which is equal to 70 Gy in conventional fractionation in 7 weeks. ${ }^{10}$

The Danish trial showed the benefit of accelerated radiotherapy in younger patients. In our study, we have opted patients upto 70 yrs. The benefit shown here is consistent with the Danish study.

In the Danish trial, the impact of reduction in overall treatment time was shown in well and moderately differentiated tumours. There was a $27 \%$ improvement in the tumour control when the overall treatment time was reduced to 5.3 weeks. In our study, the enhanced complete response in well and moderately differentiated tumours were concurring with DAHANCA 6 trial study. The Danish study reported that the whole benefit of acceleration came from improved T-site control. Since the early responding tissues has $\alpha / \beta$ ratio as that of squamous cell carcinoma of head and neck, it responds similarly to the tumour. In our study, most of the reactions are Gr-I and II (Skin Gr I 20.8\%, Gr II 75\% and Gr III 4\%). Laryngeal mucosal toxicity (Gr I 26\%, Gr II $60 \%$ and Gr III 13.3\%). Only 4 patients developed Gr III mucositis, which started at end of $4^{\text {th }}$ week and peaked at $5^{\text {th }}$ week. All these did not result in treatment break. The results from this study show that radiation is an effective modality of treatment for laryngeal cancer without any detrimental effect on survival, while preserving the larynx in our population. Randomised trials with larger number of patients are required to confirm the findings. ${ }^{11}$

Garcia-Serra et al reviewed 22 series containing 705 patients with carcinoma in situ of the vocal cord treated with radiotherapy and observed that the weighted average 5-year local control and ultimate local control rates were $87.4 \%$ and 98.4\% respectively. The results of irradiation for 519 patients with T1 and T2 N0 squamous cell carcinoma of the vocal cord treated by irradiation are as follows. The ultimate local control rates were $98 \%$ for $\mathrm{T} 1$ lesions and $96 \%$ for $\mathrm{T} 2$ lesions. The local control rates with larynx preservation rates were $95 \%$ for $\mathrm{T} 1$ lesions and $82 \%$ and $76 \%$ for $\mathrm{T} 2 \mathrm{~A}$ and $\mathrm{T} 2 \mathrm{~B}$ lesions respectively. The 5-year rates of neck control for 506 patients who received no elective neck treatment for the overall groups and for the subsets of patients who remained continuously disease free at the primary site were: T1, 99\% and 100\%; T2a, 95\% and 97\%; and T2b, $87 \%$ and $92 \%$, respectively. ${ }^{12}$

The results of definitive radiotherapy for patients with T3 glottic carcinomas are compared to those following surgery in a series of 118 patients treated at the University of Florida. Hinerman et al recently updated the University of Florida experience and reported a 5-year local control rate of $63 \%$ for 87 patients with fixed cord T3 glottic carcinomas. The 
likelihood of local control after radiotherapy is related to primary tumour volume and cartilage sclerosis. Disease free rates for $\mathrm{T} 4$ glottic carcinomas have been reported in the ranges of $40 \%-54 \%$ in various series. ${ }^{13}$

The primary endpoint was local control after radiotherapy. This endpoint was complete and persistent disappearance of disease in the primary tumour. Secondary endpoint included assessing acute toxicity rates.

With careful followup, recurrence is sometimes detected before the patient notices return of hoarseness. There is often minimal lymphoedema for 1 to 2 months after irradiation, which usually subsides or stabilises. An increase in oedema, particularly if associated with hoarseness or pain suggests recurrence, even if there is no obvious tumour. Fixation of a previously mobile vocal cord usually implies local recurrence, but the occasional patient has a fixed cord with an otherwise normal appearing larynx and without evidence of recurrence. It may be difficult to diagnose recurrence if the tumour is submucosal. Generous, deep biopsies are required. If recurrence is strongly suspected, laryngectomy may rarely be advised without biopsy-confirmed evidence of recurrence. ${ }^{14}$

\section{CONCLUSION}

In conclusion, this rather small, Single-Institutional study showed promising results and acceptable toxicities in patients with early stages laryngeal cancer. The present schedule is tolerated and can be safely used on an outpatient basis and even in old patients and patients with controlled comorbidities. Since this study was conducted in a small group, it may necessitate activation of a large phase III trial focusing on a more homogenous group of patients including also less advanced stages together with other approaches like altered fractionation regimens.

This data shows that it is feasible to do Accelerated Radiotherapy with manageable, although substantial toxicity. The compliance to therapy is high and the local response achieved with Accelerated Radiotherapy is significant. The hospital stay is reduced. Hence, it is an effective alternate regimen in centres with high work load. It also compares well with the available literature. Large sample size is required to achieve a statistically significant result with this protocol.

\section{REFERENCES}

[1] Siegel R, Naishadham D, Jemal A. Cancer statistics, 2012. CA Cancer J Clin 2012;62(1):10-29.

[2] Mendenhall WM, Werning JW, Hinerman RW, et al. Management of T1-T2 glottic carcinomas. Cancer 2004;100(9):1786-92.
[3] Luscher MS, Pedersen U, Johansen LV. Treatment outcome after laser excision of early glottic squamous cell carcinoma--a literature survey. Acta Oncol 2001;40(7):796-800.

[4] Delsupehe KG, Zink I, Lejaegere M, et al. Voice quality after narrow-margin laser cordectomy compared with laryngeal irradiation. Otolaryngol Head Neck Surg 1999;121(5):528-33.

[5] Mendenhall WM, Mancuso AA, Hinerman RW, et al. Multidisciplinary management of laryngeal carcinoma. Int J Radiat Oncol Biol Phys 2007;69(2 Suppl):S12-4.

[6] Mendenhall WM, Amdur RJ, Morris CG, et al. T1-T2N0 squamous cell carcinoma of the glottic larynx treated with radiation therapy. J Clin Oncol 2001;19(20):4029-36.

[7] Yamazaki H, Nishiyama $K$, Tanaka E, et al. Radiotherapy for early glottic carcinoma (T1N0M0): results of prospective randomized study of radiation fraction size and overall treatment time. Int J Radiat Oncol Biol Phys 2006;64(1):77-82.

[8] Le QT, Fu KK, Kroll S, et al. Influence of fraction size, total dose, and overall time on local control of T1-T2 glottic carcinoma. Int J Radiat Oncol Biol Phys 1997;39(1):115-26.

[9] Parkin DM, Muir CS, Whelan S, et al. Cancer incidence in five continents, Vol. 6. IARC scientific publication No. 120. Lyon: World Health Organization, international agency for research on cancer 1992.

[10] Maier H, Dietz A, Gewelke U, et al. Tobacco and alcohol and the risk of head and neck cancer. Clin Invest 1992;70(3):320-7.

[11] Sancho-Garnier J, Theobald S. Black (air-cured) and blond (flue-cured) tobacco and cancer risk II: pharynx and larynx cancer. Eur J Cancer 1993;29A(2):273-6.

[12] Garcia-Serra A, Hinerman RW, Amdur RJ, et al. Radiotherapy for carcinoma in situ of the true vocal cords. Head Neck 2002;24(4):390-4.

[13] Hinerman RW, Mendenhall WM, Morris CG, et al. T3 and T4 true vocal cord squamous cell carcinomas treated with external beam irradiation: a single institution's 35-year experience. Am J Clin Oncology (CCT) 2007;30(2):181-5.

[14] Mendenhall WM, Parsons JT, Stringer SP, et al. Stage T3 squamous cell carcinoma of the glottic larynx: a comparison of laryngectomy and irradiation. Int J Radiat Oncol Biol Phys 1992;23(4):725-32. 